\title{
Inhibition of Dihydrostreptomycin Binding to Mycobacterium smegmatis by Monovalent and Divalent Cation Salts
}

\author{
WILLIAM H. BEGGS* AND FRED A. ANDREWS \\ Bacteriology Research Laboratory, General Medical Research Service, Veterans Administration Hospital, \\ Minneapolis, Minnesota 55417
}

Received for publication 28 November 1975

\begin{abstract}
To better understand salt antagonism of dihydrostreptomycin (DSM) action on Mycobacterium smegmatis, the effects of monovalent and divalent cation salts on drug uptake were studied in relation to the lethal activity of DSM. In Sauton liquid medium $\mathrm{NaCl}, \mathrm{MgCl}_{2}$, and $\mathrm{SrCl}_{2}$ inhibited the initial instantaneous binding of $\left[{ }^{3} \mathrm{H}\right] \mathrm{DSM}$ to the organism and suppressed secondary uptake. These data correlated well with the capacity of each salt to prevent the lethal activity of DSM. It was concluded that monovalent and divalent cation salt antagonism of DSM action on $M$. smegmatis involves nonspecific interference with drug uptake.
\end{abstract}

Previous studies in our laboratory showed that both monovalent and divalent cation salts can antagonize the inhibitory and bactericidal effects of dihydrostreptomycin (DSM) on Mycobacterium smegmatis $(3,4)$. The mechanisms involved, however, appeared to be different for the two classes of salts (3). Results suggested that antagonism by monovalent cation salts is a nonspecific ionic strength effect. In contrast, neutralization of DSM action by $\mathrm{MgSO}_{4}$ and $\mathrm{MgCl}_{2}$ appeared to involve a divalent cation concentration-dependent mechanism. Since chloride salts of the nutritionally nonessential cations $\mathrm{Sr}^{2+}$ and $\mathrm{Ba}^{2+}$ inhibited DSM action as effectively as the chlorides of $\mathrm{Mg}^{2+}$ and $\mathrm{Ca}^{2+}(4)$, it appeared that divalent cation antagonism is dependent more upon a double positive charge than on a particular metal ion species. We postulated, therefore, that the divalent cation effect, like the ionic strength effect, probably involves nonspecific interactions that suppress cellular uptake of the aminoglycoside. Streptomycin uptake by susceptible organisms appears to be a diphasic process: an initial instantaneous binding followed by a secondary period of time-dependent uptake $(1,7,11,14)$. In the present study, evidence is presented that monovalent and divalent cation salts can interfere with both of these events. Uptake data correlated well with viability studies, showing that each salt prevented or retarded the bactericidal action of DSM.

\section{MATERIALS AND METHODS}

General. The source of $M$. smegmatis, the composition of Sauton medium, growth conditions, preparation of DSM solutions, additions of test salts, and methods used in viability studies were previously described in detail $(3,5)$. It should be stated again, however, that Sauton medium was supplemented with test salts on the basis of ionic strength $(\mu)$. From the equation $\mu=\Sigma m Z^{2} / 2$, where $m$ is the ion molarity and $Z$ is the ion charge, molarities were calculated that gave desired $\mu$ values.

$\left[{ }^{3} \mathrm{H}\right] \mathrm{DSM}$ binding and uptake experiments. Labeled drug $\left(\left[{ }^{3} \mathrm{H}\right] \mathrm{DSM}\right.$ sesquisulfate) was purchased from Amersham/Searle, Arlington Heights, Ill. The material had a specific activity of $3.0 \mathrm{Ci} / \mathrm{mmol}(2.1$ $\mathrm{mCi} / \mathrm{mg}$ ). Aqueous solutions of labeled and unlabeled DSM sesquisulfate were mixed to give a working stock solution that contained $2.0 \mu \mathrm{g}$ of $\left[{ }^{3} \mathrm{H}\right] \mathrm{DSM}$ free base plus $18 \mu \mathrm{g}$ of DSM-free base per ml (total of $20 \mu \mathrm{g}$ of DSM, and $5.0 \mu \mathrm{Ci} / \mathrm{ml}$ ). Overnight $16-$ to $18-\mathrm{h}$ Sauton cultures of $M$. smegmatis grown at $37 \mathrm{C}$ with rotary shaking $(150 \mathrm{rpm})$ were diluted with fresh medium to an optical density $(600 \mathrm{~nm})$ of $0.05(0.07$ mg [dry weight] of cells per ml). Desired concentrations of salts were added to $100-\mathrm{ml}$ volumes of this suspension in 250-ml Erlenmeyer flasks. Labeled drug was then added at a concentration of $0.2 \mu \mathrm{g}$ of [ $\left.{ }^{3} \mathrm{H}\right] \mathrm{DSM}$-free base and $0.05 \mu \mathrm{Ci} / \mathrm{ml}$. These cultures were incubated at either 4 or $37 \mathrm{C}$ with rotary shaking. At selected time intervals, the cells contained in $8.0-\mathrm{ml}$ samples were collected on bacteriological filter membranes (diameter, $2.54 \mathrm{~cm}$; pore size, 0.8 $\mu \mathrm{m})$ under negative pressure. The cell-containing filter membranes were then washed three times with 2-ml volumes of either deionized water or drugfree Sauton medium, dried, and assayed for radioactivity as previously described (2). In the $37 \mathrm{C}$ experiments, optical densities at $600 \mathrm{~nm}$ were determined at appropriate sampling times and converted to milligrams (dry weight) of cells per milliliter from a standard curve. Counting data were corrected for filter membrane adsorption of radioactivity in the following manner. Labeled drug was added at 0.2 $\mu \mathrm{g} / \mathrm{ml}$ to portions of Sauton medium with and without appropriate concentrations of the various test 
salts. An 8.0-ml volume of each solution was passed through a separate filter membrane, followed by an 8.0-ml volume of unlabeled cell suspension (optical density at $600 \mathrm{~nm}=0.05$ ). These samples were then washed twice with either deionized water or Sauton medium, dried, and counted. Counts obtained in these blank samples were subtracted from values obtained in the corresponding experimental samples.

\section{RESULTS}

Both $\mathrm{MgCl}_{2}$ and $\mathrm{NaCl}$ protected M. smegma$t$ is from the lethal action of $0.2 \mu \mathrm{g}$ of DSM per $\mathrm{ml}$ (Fig. 1). It is apparent, however, that $\mathrm{MgCl}_{2}$ was more effective than $\mathrm{NaCl}$. Note that a high level of $\mathrm{NaCl}(0.08 \mathrm{M}, \mu=0.08)$ mimicked the protection provided by $\mathrm{MgCl}_{2}(0.01 \mathrm{M}, \mu=$ 0.03). The complete protection from lethal activity provided by $\mathrm{SrCl}_{2}(0.01 \mathrm{M}, \mu=0.03)$ was consistent with earlier findings (4) and made it increasingly doubtful that divalent cation salt antagonism of DSM involves a specific physiological or metabolic effect. Therefore, further experiments were designed to test the possibility that each of the salts inhibits DSM action against $M$. smegmatis by nonspecific interference with drug uptake.

The kinetics of [ $\left.{ }^{3} \mathrm{H}\right] \mathrm{DSM}$ uptake by $M$. smegmatis are shown in Fig. 2. A diphasic curve similar to that shown in streptomycin uptake studies with other organisms $(1,7,11,14)$ was seen in the results with water-washed cells.

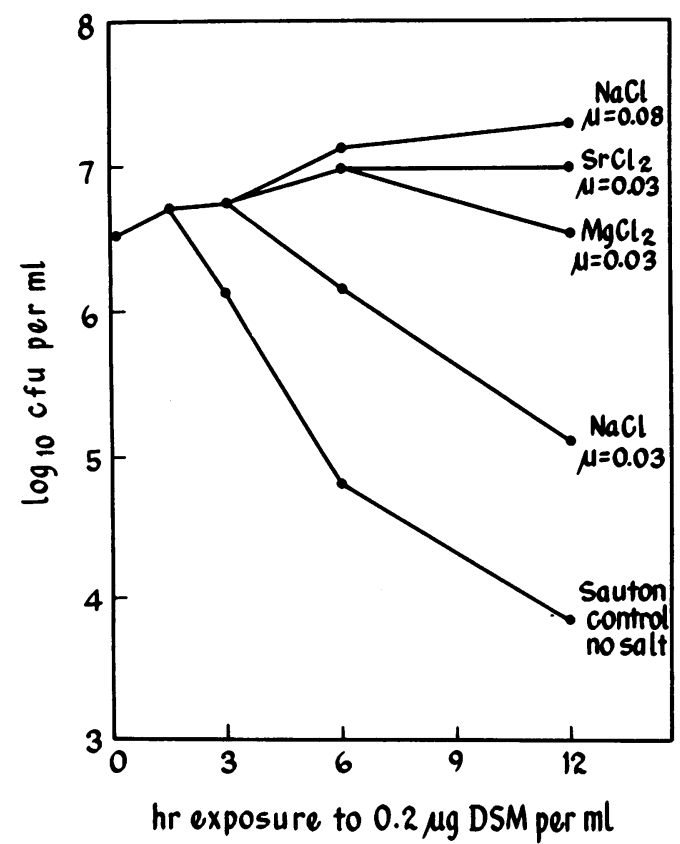

Fig. 1. Protection of $M$. smegmatis from the lethal action of DSM by monovalent and divalent cation salts. $\mu$, Calculated ionic strengths of added salts.

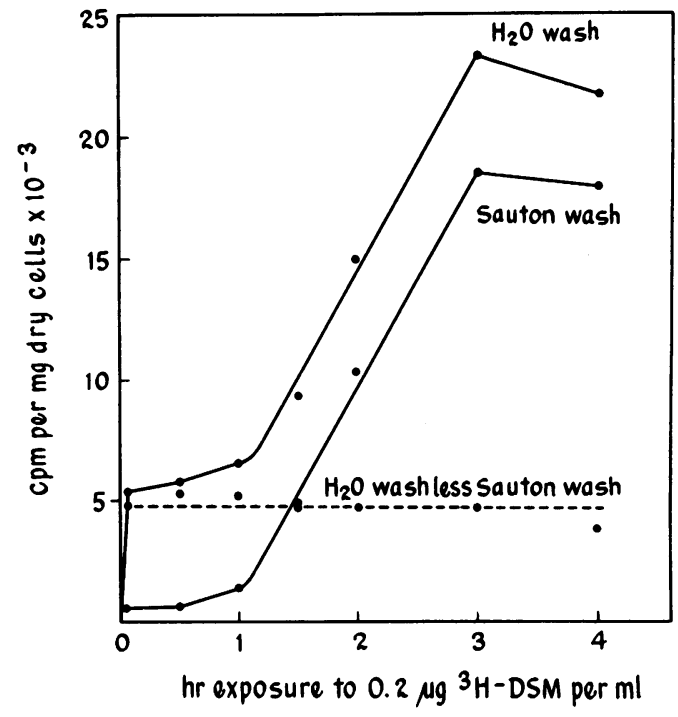

Fig. 2. Kinetics of $\left[{ }^{3} \mathrm{H}\right] D S M$ uptake by $M$. smegmatis at 37 C. Comparison of cells washed three times with deionized water (water wash) to cells washed three times with Sauton medium (Sauton wash).

After an apparent instantaneous binding of the drug, there was a 60 -min plateau followed by a rapid linear period of drug uptake lasting $2 \mathrm{~h}$. The ease with which $90 \%$ of the drug bound during the first minute was removed by Sauton (salt solution) washing indicated a weak drugcell interaction that may primarily involve electrostatic attraction (11). Approximately $10 \%$ of the $\left[{ }^{3} \mathrm{H}\right] \mathrm{DSM}$ taken up during the first minute was rather firmly bound, as evidenced by its resistance to Sauton washing. Note in Fig. 2 that for all of the time periods selected for sampling, subtraction of Sauton-wash from water-wash values gave counts approximating instantaneous binding that plotted as a horizontal line. This shows that essentially all drug taken up after initial instantaneous binding was rather firmly bound.

$\mathrm{NaCl}(0.08 \mathrm{M}, \mu=0.08)$ protected $M$. smegmatis from the lethal action of $0.2 \mu \mathrm{g}$ of DSM per $\mathrm{ml}$ when both were added at time zero (Fig. 1). When $\mathrm{NaCl}$ was added $45 \mathrm{~min}$ after DSM (i.e., the late plateau period of the uptake curve in Fig. 2), the same high level of protection was observed (Fig. 3). Although addition of $\mathrm{NaCl}$ after $90 \mathrm{~min}$ of previous DSM exposure delayed the onset of measurable bactericidal activity, it did not prevent such activity. At $90 \mathrm{~min}$, secondary uptake of DSM was well under way (Fig. 2). These data suggested that binding to critical sites of DSM action is associated with the Saution-stable or firmly bound fraction.

The experiment presented in Fig. 4 shows the inhibitory effects of the various salts on 
$\left[{ }^{3} \mathrm{H}\right] \mathrm{DSM}$ uptake by $M$. smegmatis (as measured in Sauton-washed cells). The rate and extent of uptake was strongly inhibited in each case. Low-level $\mathrm{NaCl}$ was the least suppressive, followed in increasing order of effectiveness by $\mathrm{MgCl}_{2}$, high-level $\mathrm{NaCl}$, and $\mathrm{SrCl}_{2}$. These data correlated well with the viability studies seen in Fig. 1. Note that between 3 and $4 \mathrm{~h}$ uptake in the presence of $0.03 \mathrm{M} \mathrm{NaCl}$ approached the

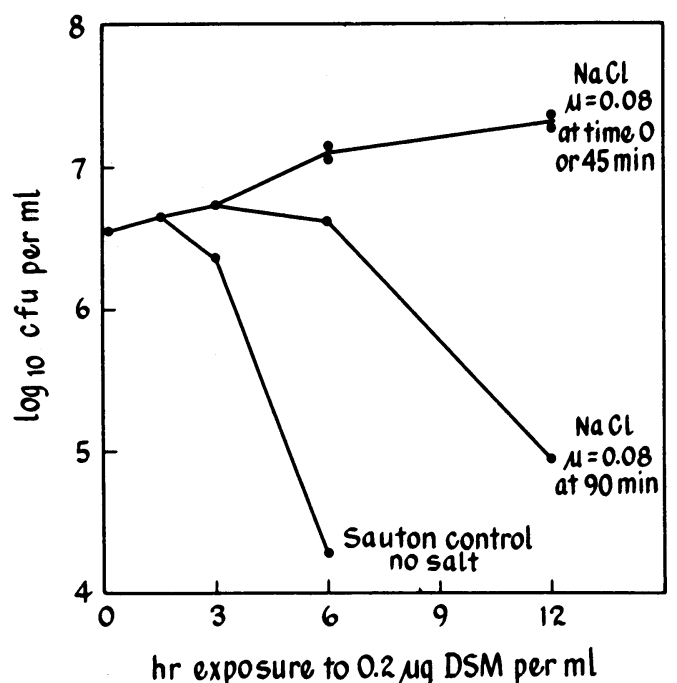

Fig. 3. Protection of $M$. smegmatis from the lethal action of DSM by $0.08 \mathrm{M} \mathrm{NaCl}$ (ionic strength, 0.08) added at time zero and at 45 and 90 min after DSM.

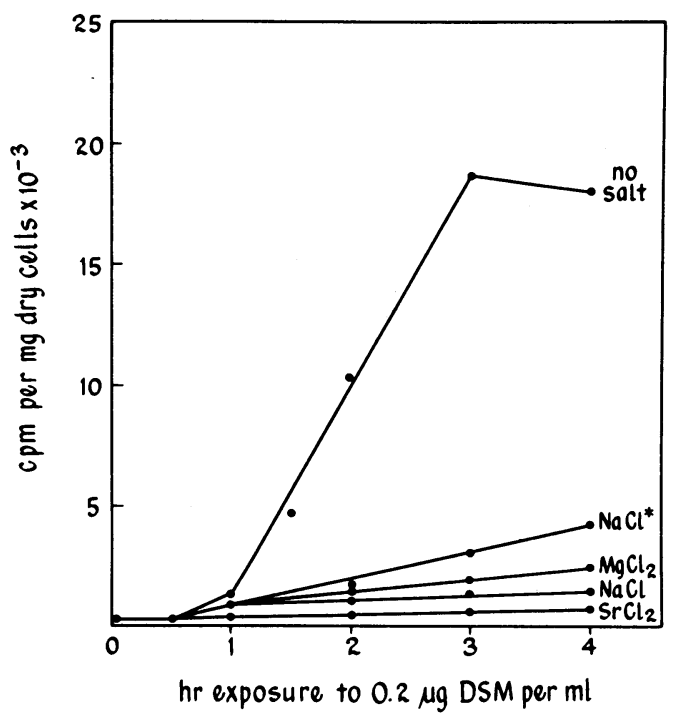

Fig. 4. Effects of various salts on $\left[{ }^{3} \mathrm{H}\right] D S M$ uptake by $\mathrm{M}$. smegmatis at $37 \mathrm{C} . \mathrm{MgCl}_{2}$ and $\mathrm{SrCl}_{2}$ tested at $0.01 \mathrm{M}$ (ionic strength, 0.03 ). $\mathrm{NaCl}$ tested at (asterisk) $0.03 \mathrm{M}$ (ionic strength, 0.03)* and at $0.08 \mathrm{M}$ (ionic strength, 0.08). Uptake measured in Sautonwashed cells.
4,000- to 5,000-counts/min level measured at 90 min in the control culture containing no added salt. It is interesting that measurable bactericidal activity began in the control and in the $0.03 \mathrm{M} \mathrm{NaCl}$-containing cultures after $90 \mathrm{~min}$ and $3 \mathrm{~h}$, respectively (Fig. 1). Previous reports by other workers showed that cellular streptomycin can reach levels in considerable excess of that required for inhibitory activity $(14,15)$. The $2 \times 10^{4}$-counts/min level reached in the control (no salt) culture at $3 \mathrm{~h}$ (Fig. 4) supports these earlier findings.

The effects of salts on instantaneous binding of DSM to $M$. smegmatis cells are shown in Fig. 5. To minimize complications imposed by secondary uptake, these studies were performed at $4 \mathrm{C}$. The salts markedly blocked instantaneous binding, and the degree of inhibition correlated well with uptake studies (Fig. 4) and with the ability of each salt to prevent the lethal action of DSM (Fig. 1). Instantaneous binding was measured with water-washed cells. As a control in the $4 \mathrm{C}$ experiment (Fig. 5), duplicate samples were taken from the culture containing no added salt. One sample was water washed, and the second was Sauton washed. The negligible levels of bound radioactivity measured in the

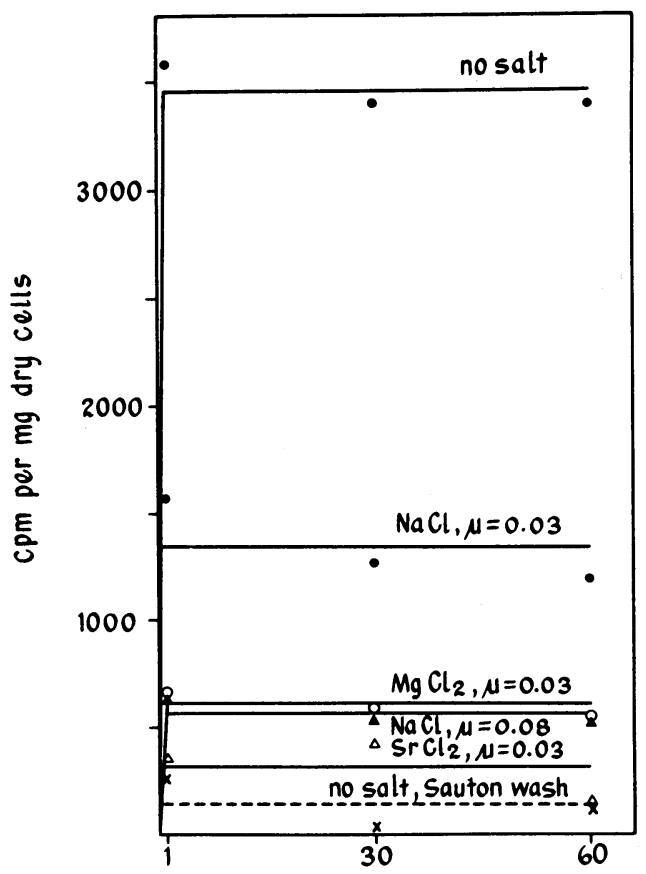

min exposure to $0.2 \mu g^{3} \mathrm{H}$-DSM per $\mathrm{ml}$ at $4 \mathrm{C}$

Fig. 5. Effects of various salts on initial binding of $\left.{ }^{3} \mathrm{H}\right] D S M$ by $M$. smegmatis at $4 \mathrm{C} . \mu$, Calculated ionic strengths of added salts. Binding measured in water-washed cells, except where Sauton wash is indicated. 
latter indicated that over $95 \%$ of the cell-associated drug was Sauton labile and therefore weakly bound.

\section{DISCUSSION}

It has been clearly established that inorganic salts can adversely affect the action of aminoglycoside antibiotics on various bacterial species $(3,6,8,10,12,13,16,19)$. As shown in earlier work from our laboratory $(3,4)$ and confirmed in the present report, both monovalent and divalent cation salts can inhibit DSM activity against $M$. smegmatis. Although differences in the characteristics of DSM antagonism by the two different types of salts were observed (3), we felt that both effects probably involved interference with drug uptake. The main purpose of the present investigation was to test this hypothesis. Salt antagonism of $\left[{ }^{14} \mathrm{C}\right]$ streptomycin uptake by bacteria has been reported $(6,9$, 17), and recently Ramirez-Ronda et al. (18) showed that $\mathrm{Mg}^{2+}$ and $\mathrm{Ca}^{2+}$ inhibited initial rapid binding $\left[{ }^{3} \mathrm{H}\right]$ gentamicin to Pseudomonas aeruginosa. In the present study, we examined and compared the effects of monovalent and divalent cation salts on the different phases of $\left[{ }^{3} \mathrm{H}\right] \mathrm{DSM}$ uptake by $M$. smegmatis.

Consistent with capacities to prevent or retard the lethal action of $\mathrm{DSM}, \mathrm{NaCl}, \mathrm{MgCl}_{2}$, and $\mathrm{SrCl}_{2}$ all markedly inhibited both the rate and extent of Sauton-stable drug uptake. Even more interesting, and perhaps of greater significance, was the inhibitory effect that each salt had on primary or instantaneous Sauton-labile binding of DSM. Each salt blocked this reaction to a degree that roughly coincided with ability to prevent lethality. These data indicated clearly that both types of salts interfere with DSM uptake. On both molar- and ionicstrength bases, $\mathrm{MgCl}_{2}$ and $\mathrm{SrCl}_{2}$ were more effective DSM antagonists than $\mathrm{NaCl}$. This may be not only due to the presence of a double positive charge, but also to the particular distribution of these charges on the cations.

Studies on the kinetics of $\left[{ }^{3} \mathrm{H}\right] \mathrm{DSM}$ uptake indicated that weak binding precedes appreciable Sauton-stable binding, but we did not show conclusively that weak binding is a prerequisite for secondary uptake. In the presence of salts, however, decreases in Sauton-labile binding correlated well with decreases in secondary uptake. If we can assume that weak binding is a prerequisite for secondary uptake, it is probable that inhibition of the initial rapid weakbinding reaction is the key event responsible for monovalent and divalent cation salt antagonism of DSM action on $M$. smegmatis.

\section{LITERATURE CITED}

1. Anand, N., B. D. Davis, and A. K. Armitage. 1960. Uptake of streptomycin by Escherichia coli. Nature (London) 185:23-24.

2. Beggs, W. H., and F. A. Andrews. 1974. Chemical characterization of ethambutol binding to Mycobacterium smegmatis. Antimicrob. Agents Chemother. 5:234239.

3. Beggs, W. H., and F. A. Andrews. 1975. Inhibition of dihydrosteptomycin action on Mycobacterium smegmatis by monovalent and divalent cation salts. Antimicrob. Agents Chemother. 7:636-639.

4. Beggs, W. H., and F. A. Andrews. 1975. Nonspecificity in the divalent cation antagonism of dihydrostreptomycin action on Mycobacterium smegmatis. Res. Commun. Chem. Pathol. Pharmacol. 10:185-188.

5. Beggs, W. H., and J. W. Jenne. 1967. Mechanism for the pyridoxal neutralization of isoniazid action on Mycobacterium tuberculosis. J. Bacteriol. 94:793-797.

6. Beggs, W. H., and N. E. Williams. 1971. Protection of Mycobacterium smegmatis from ethambutol and streptomycin inhibition by $\mathrm{MgSO}_{4}$ and polyamines. Infect. Immun. 3:496-497.

7. Beggs, W. H., and N. E. Williams. 1971. Streptomycin uptake by Mycobacterium tuberculosis. Appl. Microbiol. 21:751-753.

8. Berkman, S., R. J. Henry, and R. D. Housewright. 1947. Studies on streptomycin. I. Factors influencing the activity of streptomycin. J. Bacteriol. 53:567-574.

9. Berkman, S., R. J. Henry, R. D. Housewright, and J. Henry. 1948. Streptomycin. IV. Adsorption of streptomycin by susceptible and resistant bacteria. Proc. Soc. Exp. Biol. Med. 68:65-70.

10. Donovick, R., A. P. Bayan, P. Canales, and F. Pansy 1948. The influence of certain substances on the activity of streptomycin. III. Differential effects of various electrolytes on the action of streptomycin. J. Bacteriol. 56:125-137.

11. Dubin, D. T., R. Hancock, and B. D. Davis. 1963. The sequence of some effects of streptomycin in Escherichia coli. Biochim. Biophys. Acta 74:476-489.

12. Gilbert, D. N., E. Kutscher, P. Ireland, J. A. Barnett, and J. P. Sanford. 1971. Effect of the concentrations of magnesium and calcium on the in vitro susceptibility of Pseudomonas aeruginosa to gentamicin. J. Infect. Dis. 124:S37-S45.

13. Green, S. R., and S. A. Waksman. 1948. Effect of glucose, peptone, and salts on streptomycin activity. Proc. Soc. Exp. Biol. Med. 67:281-283.

14. Hurwitz, C., and C. L. Rosano. 1962. Accumulation of label from C $\mathrm{C}^{14}$-streptomycin by Escherichia coli. J. Bacteriol. 83:1193-1201.

15. Kogut, M., J. W. Lightbrown, and P. Isaacson. 1966. The intracellular accumulation of ${ }^{14} \mathrm{C}$-streptomycin by Escherichia coli strain B in relation to its growthinhibitory effect. J. Gen. Microbiol. 42:333-344.

16. Medeiros, A. A., T. F. O'Brien, W. E. C. Wacker, and N. F. Yulug. 1971. Effect of salt concentration on the apparent in vitro susceptibility of pseudomonas and other gram negative bacilli to gentamicin. J. Infect. Dis. 124:S59-S64.

17. Plotz, P. H., D. T. Dubin, and B. D. Davis. 1961. Influence of salts on the uptake of streptomycin by Escherichia coli. Nature (London) 191:1324-1325.

18. Ramirez-Ronda, C. H., R. K. Holmes, and J. P. Sanford. 1975. Effects of divalent cations on binding of aminoglycoside antibiotics to human serum proteins and to bacteria. Antimicrob. Agents Chemother. 7:239-245.

19. Zimelis, V. M., and G. G. Jackson. 1973. Activity of aminoglycoside antibiotics against Pseudomonas aeruginosa: specificity and site of calcium and magnesium antagonism. J. Infect. Dis. 127:663-669. 